\title{
KELENTENG: BENTENG TERAKHIR DAN TITIK AWAL PERKEMBANGAN KEBUDAYAAN TIONGHOA DI INDONESIA
}

\author{
M. Herwiratno
}

Akademi Bahasa Asing, Bina Sarana Informatika, Jl. Cipinang Pulo Maja No.1, Jatinegara-Jakarta Timur herwiratno@yahoo.com

\begin{abstract}
ABSRACT
This article discussed about the degradation of culture among Tionghoa society in Indonesia due to public pressure during Orde Baru era. It is fortune during the hard time, kelenteng as the place for prayer for Tionghoa society also had became place of protection for many forms of culture, such as life philosophy, ritual, and art. And now after the political pressure removed and the Tionghoa society wanted to know their culture, kelenteng becomes one of the important sources for knowledge about Tionghua's culture. But, that apparently was not easy because many kelenteng were in sad condition and being pushed away by the Tionghoa society itself.
\end{abstract}

Keywords: kelenteng, Orde Baru, Tionghoa

\begin{abstract}
ABSTRAK
Artikel menelaah tentang kemerosotan budaya di kalangan masyarakat Tionghoa di Indonesia akibat tekanan politik semasa Orde Baru. Beruntunglah pada masa sulit tersebut, kelenteng sebagai sebuah tempat ibadah masyarakat Tioanghoa juga menjadi tempat perlindungan berbagai bentuk budaya, seperti ajaran falsafah hidup, ritual, dan kesenian. Dan sekarang setelah tekanan politik tersebut menghilang dan masyarakat Tionghoa ingin kembali mengenal budayanya, seharusnya kelenteng menjadi salah satu sumber pentingnya. Akan tetapi, ternyata hal itu tidaklah mudah karena banyak kelenteng dalam kondisi mengenaskan dan dijauhi masyarakat Tionghoa sendiri.
\end{abstract}

Kata Kunci: kelenteng, Orde Baru, Tionghoa 


\section{PENDAHULUAN}

Beberapa waktu lalu ketika sekelompok mahasiswa Tionghoa sebuah universitas swasta mendapat tugas lapangan mata kuliah Kebudayaan China untuk mengunjungi kelenteng di Jakarta, mereka kemudian malah minta ditemani dosennya. Alasannya? Mereka belum pernah mengunjungi kelenteng dan takut kepada para penjaga kelenteng yang menurut mereka biasanya galak! Mungkin kedengaran aneh tetapi memang peristiwa kaum muda Tionghoa Indonesia yang takut atau tidak lagi mengenal kelenteng sebagai salah satu pusat budayanya sendiri sudah menjadi gejala umum di Indonesia sekarang ini. Sepertinya, hanya untuk sekedar mengenal kembali budayanya sendiri saja mereka begitu ketakutan.

Kalau ditelusuri ke belakang, gejala kaum muda Tionghoa Indonesia yang tidak mengenal lagi budayanya ini bukanlah tanpa sebab yang ringan. Tekanan politik Orde Baru terhadap masyarakat Tionghoa menjadi sebab utamanya. Selama 32 tahun, segala macam bentuk budaya Tionghoa dilarang. Bahasa dan tulisan China dilarang digunakan yang akibatnya koran dan majalah berbahasa China hampir seluruhnnya dilarang terbit, sekolah berbahasa China ditutup, dan bahkan nama China pun harus diganti. Berbagai perayaan tradisional tidak boleh dirayakan secara umum dan berbagai kesenian dilarang ditampilakan.

Walaupun tingkat keketatan pelarangan ini tidak sama di setiap daerah di Indonesia, tetapi tekanan politik terhadap budaya China ini menyebabkan berkurangnya atau bahkan tidak berjalannya proses transfer budaya China dari generasi tua ke generasi mudanya. Dan sekarang, setelah perubahan politik Indonesia yang lebih kondusif terhadap kebudayaan Tionghoa, ternyata akibatnya pasungan budaya tersebuat sudah sedemikian parah.

\section{PEMBAHASAN}

\section{Kelenteng sebagai Tempat Perlindungan Budaya}

Walaupun mendapat tekanan politik yang sangat kuat pada masa Orde Baru, tetapi beruntunglah budaya China masih memiliki sedikit tempat perlindungan, yaitu kelenteng. Kelenteng yang merupakan tempat ibadah sebagian besar masyarakat Tionghoa Indonesia tidak hanya menjadi tempat sembahyang tetapi juga menjadi pusat kegiatan sosial dan kesenian.

Pada masa Orde Baru, kepercayaan masyarakat Tionghoa yang sarat dengan berbagai upacara dan perayaan ritual serta diiringi kesenian yang mengandung banyak nilai budaya masih dapat dilaksanakan dalam kelenteng, walaupun dalam porsi yang lebih kecil atau bahkan dengan sembunyisembunyi. Tak heran kalau kelenteng menjadi benteng terakhir perlindungan budaya Tionghoa Indonesia selama masa Orde Baru. Dan masuk akal pula kalau kemudian setelah berakhirnya tekanan Orde Baru, kelenteng diharapkan menjadi salah satu titik awal kebangkitan budaya Tionghoa di Indonesia. Akan tetapi, menilik beberapa contoh peristiwa yang terjadi pada kaum muda Tionghoa Indonesia tersebut, rasanya masih perlu waktu untuk kembali mengenalkan kelenteng sebagai salah satu sumber belajar kembali budaya China di Indonesia.

\section{'Kelenteng': Sebutan Khas Indonesia}

Pada jaman dahulu di negara China, bangunan tempat ibadah hanya boleh dibangun oleh kaisar, raja, atau pejabat tinggi. Demikian pula yang terjadi di Indonesia. Masyarakat China Perantauan di Indonesia yang telah sukses, kaya, dan menjadi pejabat (Opsir Tionghoa yang diangkat 
Belanda) biasanya berpatungan untuk membangun sebuah bangunan tempat ibadah sebagai tanda bakti atau amalan tertinggi. Bangunan tempat ibadah itu tidak hanya dibangun sebagai tempat pemujaan dan ritual tetapi juga berfungsi sebagai pusat kegiatan sosial dan kebudayaan. Berbagai acara amal kemanusiaan, perayaan, dan pagelaran budaya diselenggarakan di areal bangunan itu. Dapat dikatakan juga bahwa waktu itu tempat ibadah juga menjadi pusat kegiatan masyarakat Tionghoa.

Entah kapan sebenarnya kata 'kelenteng' mulai digunakan untuk menyebut tempat ibadah kaum Tionghoa ini. Pada jaman pendudukan Belanda, ada sebuah kata yang digunakan untuk menyebutnya, walaupun sedikit aneh di telinga masyarakat sekarang, yaitu 'gereja'! Asal kata kelenteng sendiri juga simpang siur. Ada yang mengatakan berasal dari kata Kwan Im Ting (Kuil Dewi Kwan Im) yang kemudian dilafalkan oleh lidah Jawa menjadi kelenteng. Ada pula yang menduga bunyi genta 'teng-teng-teng' yang sering terdengar dari dalam bangunan ibadah ini menjadi awal dari kata kelenteng. Hanya saja kata kelenteng ini lebih populer di Jawa. Di luar Jawa, kata 'Toapekong' atau 'Tepekong', yaitu kata sebutan untuk Dewa Air, lebih populer untuk menyebut tempat ibadah masyarakat Tionghoa ini.

Di negeri China sendiri sebenarnya tak ada istilah umum yang khusus untuk menyebut jenis tempat ibadah kaum Tionghoa ini yang makna seluas kata 'kelenteng' di Indonesia. Biasanya mereka menamai sebuah tempat ibadah dari kekhususan aliran kepercayaannya. Walaupun kata miao sering digunakan dengan salah kaprah untuk menyebut tempat ibadah tetapi kata miao dan ci sendiri sebenarnya lebih tepat digunakan untuk menyebut tempat yang memuja 'arwah suci' atau shen ming, misalnya, Kong Miao (kuil peringatan untuk Kong zi/Konfusius) atau Guan Di Miao (kuil peringatan dewa Guan Di/Kuan Kong). Kata yuan, gong, dan guan adalah ciri dari nama tempat ibadah yang memuja dewa-dewi Taoisme, misalnya, kelenteng Jin De Yuan (Kim Tek I) di Jakarta atau kelenteng Ci An Gong (Cu An Kiong) di Lasem. Kata si dan an lebih menandakan bahwa tempat ibadah tersebut dari Budhisme, misalnya, kelenteng Da Jue Si (Tay Kak Si) di Semarang atau yang paling terkenal adalah Shao Lin Si, yaitu kuil Shao Lin yang banyak muncul di film-film kungfu.

Walaupun demikian, di Indonesia, pembagian nama menurut ciri khas aliran kepercayaan tersebut tidak berlaku atau bahkan tidak diketahui oleh banyak orang. Kebanyakan sebuah tempat ibadah kaum Tionghoa itu menampung dari ketiga aliran, yaitu Taoisme, Konfusianisme, dan Budhisme atau yang sering disebut San Jiao (Sam Kao) atau Tri Dharma. Masuk akal kalau kemudian arca dari para dewa-dewi dari ketiga ajaran itu berbaur dan bernaung di bawah satu atap. Istilah 'kelenteng' menjadi terasa lebih pas digunakan untuk penyebutan rumah ibadah Tionghoa di Indonesia.

\section{Multifungsi Kelenteng}

Seperti umumnya tempat ibadah, fungsi utama kelenteng adalah sebagai tempat ibadah. Dan juga seperti banyak tempat ibadah lain, kelenteng juga merupakan tempat kegiatan sosial. Akan tetapi, di Indonesia, khususnya di Jawa, kelenteng tua juga menjadi tempat situs sejarah dan pelestarian budaya Tionghoa, bahkan menjadi tempat rajutan budaya antara kebudayaan Tionghoa dengan kebudayaan lain di Jawa.

\section{Kelenteng sebagai Tempat Sumber Ajaran Spiritual}

Sebagai tempat ibadah, dalam sebuah kelenteng yang beraliran Tri Dharma pastilah terdapat arca dewa-dewi dari ketiga aliran, Daoisme, Konfusianisme, dan Budhisme. Sebenarnya, banyak ajaran moral yang dapat dipelajari oleh para umat dari para dewa-dewi ini karena sebagian besar dari dewa-dewi Tionghoa pada awalnya adalah manusia biasa yang karena kesucian jiwa, perbuatan baik, atau kemampuannya di bidang tertentu kemudian dihormati dan diangkat menjadi dewa atau dewi. 
Misalnya saja, dewi Tian Shang Sheng Mu atau dewi Ma Zu atau di Indonesia lebih dikenal dengan Macopo/Makupo. Dewi dari ajaran Taoisme ini awalnya adalah gadis nelayan yang karena kesucian hati dan ilmunya yang tinggi kemudian diangkat menjadi Dewi Laut sebagai pelindung para nelayan dan perantauan. Dewa Guan Di atau lebih populer dengan sebutan dewa Koan Kong, awalnya adalah panglima perang pada jaman Tiga Negara yang bernama Guan Yu. Karena kesetiaan dan budi hatinya, penganut Taoisme mengangkatnya menjadi dewa kesetiaan dan pelindung bahaya peperangan, diangkat menjadi dewa pelindung kesusastraan oleh penganut Konghuchu dan dipercaya sebagai dewa penjaga dharma oleh kaum Budhis. Masih terdapat banyak lagi dewa-dewi dalam kepercayaan masyarakat Tionghoa. Hampir setiap profesi memiliki dewa-dewinya masing-masing, seperti petani, peternak sutera, pembuat dan pedagang kertas, tukang kayu, pengerajin perhiasan, sastrawan, tabib, dan bahkan tukang cukur pun punya dewa-dewi pelindungnya masing-masing. Nilai ajaran atau sifat dan perbuatan mulia dari para dewa-dewi itulah yang dapat dipelajari kembali oleh kaum muda Tionghoa Indonesia ketika berkunjung ke sebuah kelenteng.

\section{Kelenteng sebagai Penanda Sejarah Perkembangan Masyarakat Tionghoa}

Seperti bangunan lainnya, sebuah kelenteng biasanya memiliki semacam prasasti pendirian yang tercantum tahun pendiriannya. Kelenteng tertua disuatu daerah dapat dijadikan acuan bahwa di masa itu di daerah tersebut sudah terdapat pemukiman Tionghoa.

Dewa-dewi utama dalam sebuah kelenteng juga dapat menjadi salah satu acuan sejarah perkembangan perekonomian masyarakat Tionghoa di suatu daerah. Bila Dewi Laut yang menjadi dewi utama dalam sebuah kelenteng maka dapat diperkirakan bahwa masyarakat Tionghoa di daerah itu awalnya adalah kaum pedagang antarpulau atau kaum nelayan. Tidak mengherankan bila dewi ini banyak di puja di daerah pesisir pantai Utara Jawa. Akan tetapi, bila Dewa Bumi yang menjadi dewa utama maka kemungkinan besar masyarakat Tionghoa di sekitar kelenteng tersebut mengandalkan hasil pertanian dan perkebunan.

Nama marga dari dewa-dewi utama juga dapat mencerminkan marga apa yang dominan dalam masyarakat Tionghoa di daerah tersebut. Misalnya, Dewi Laut Tian Shang Sheng Mu nama aslinya adalah Lim Bik Nio. Jadi, dapat diperkirakan banyak marga Lim/Lin yang bermukim disekitar kelenteng tersebut. Bahkan, beberapa marga tertentu membangun kelenteng khusus untuk marganya sendiri, tentu saja dengan dewa/dewi utama yang berasal dari marganya sendiri.

Kaum Tionghoa Indonesia pun menyumbang dewa pujaan. Laksamana Cheng He dari dinasti Ming yang dalam tujuh ekspedisi lautnya (1405-1436) pernah berkunjung ke Nusantara kemudian diangkat menjadi dewa Sam Po Kong dan sangat dipuja di beberapa wilayah di Indonesia, khususnya di Semarang. Kwe Lak Kwa yang menjadi salah satu pimpinan perlawanan terhadap kekejaman Belanda terhadap kaum Tionghoa di Batavia (1740) kemudian di puja menjadi dewa yang bergelar $Z e$ Hai Zhen Ren. Arcanya terdapat dan dipuja di kelenteng kota Jakarta, Tegal, Pekalongan, dan Semarang. Tan Ke Wi dan Oei Ing Kiat, pimpinan perjuangan melawan Belanda di wilayah JuawanaRembang-Lasem (1742-1751) memiliki kelenteng pemujaannya sendiri dengan gelar Yi Yong Gong. Dari uraian tersebut, kelenteng tidak hanya sebagai tempat ibadah tetapi juga menyimpan data sejarah yang menjadi salah satu acuan untuk mempelajari sejarah perkembangan masyarakat Tionghoa di sekitarnya.

\section{Kelenteng sebagai Sumber Simbol Ajaran Berbagai Kepercayaan}

Filsuf besar China Konfusius pernah berkata, "Kata-kata tidak bisa mengungkapkan kedalaman bahasa, dan bahasa tidak mampu mengungkapkan kedalaman arti.” Oleh karena itulah bangsa China mengungkapkan banyak hal dengan simbol. Wajar pula, bila lebih dicermati, bangunan sebuah kelenteng tua biasanya akan penuh dengan simbol dalam berbagai bentuk yang sarat makna. 
Pada umumnya, bagian depan kiri-kanan sebuah kelenteng dijaga oleh arca sepasang singa sebagai penolak mara bahaya. Arca sepasang naga yang biasanya terdapat di atap kelenteng melambangkan perlindungan, kekuasaan, dan juga keberuntungan. Naga Ikan atau Long $Y u$, yaitu naga bersirip dan berekor ikan mengajarkan ketekunan dan kerja keras dalam meraih keberhasilan. Ukiran burung Hong atau Finiks seringkali dipasangkan dengan Naga sebagai perlambang keserasian dan keseimbangan Yin Yang. Kemunculan burung Hong yang membawa keberuntungan dan kesejahteraan dipercaya akan membuat dunia damai dan tenteram. Hewan mitos Kilin/Qilin/Unicorn yang menampakkan diri ketika Konfusius dilahirkan merupakan lambang dari kebajikan sempurna, umur panjang, kebesaran, kepatuhan, keturunan yang cemerlang, serta pemerintahan yang bijak. Kura-kura dan bangau yang berumur panjang selalu selalu menjadi lambang harapan manusia akan panjang umur dan bermartabat. Berbagai bentuk hiasan dan ukiran kelelawar dimaksudkan untuk menyimbolkan keberuntungan dan kebahagiaan karena dalam bahasa Mandarin sama-sama berbunyi fu .

Tidak hanya simbol hewan, berbagai macam tumbuhan dan buah-buahan pun memiliki makna, misalnya ukiran Bunga Empat Musim (Magnolia, Peony dan Teratai, Chrysantimum, serta Plum) yang melambangkan kecantikan, keperawanan, kemurnian, dan ketulusan. Jamur Ling Zhi dan bambu melambangkan harapan akan umur panjang. Buah apel (ping-guo) sering menghiasi sesajian di altar karena melambangkan keselamatan (mandarin: ping-an). Jeruk (juzi) hampir tak pernah ketinggalan di setiap acara ritual karena membawa simbol rejeki-keberuntungan. Pohon pisang yang gampang tumbuh anak disekitarnya menyebabkan buah pisang digunakan sebagai lambang harapan akan banyaknya keturunan.

Selain simbol hewan dan tumbuhan, adegan cerita klasik China juga sering dijumpai terlukis di dinding maupun pilar bangunan kelenteng. Dari cerita Perang Tiga Negara (San Guo/Sam Kok) dapat dipelajari berbagai sifat manusia. Cerita Dua Puluh Empat Anak Berbakti (Ershisi Xiao) berisi dua puluh empat cerita mengenai contoh bakti anak terhadap orang tuanya sesuai ajaran Konghuchu. Kisah Perjalanan Ke Barat (Xi You Ji) mencari kitab suci Budha juga menyampaikan banyak ajaran kehidupan. Belum lagi berbagai duilian atau papan-papan syair dalam aksara China yang pasti penuh makna.

Di pulau Jawa, kelenteng tua yang biasanya dibangun oleh ahli bangunan dan ukiran yang didatangkan langsung dari China dan dibantu oleh ahli lokal. Kerja sama ahli dari China dan Jawa ini menghasilkan ciri khas tertentu. Di kelenteng daerah Pesisir Utara Jawa Tengah, ukirannya terlihat rumit dan 'kecil', serupa dengan ukiran daerah Jepara-Kudus sedangkan di kelenteng Surabaya, hiasan ukirannya terlihat 'lebih besar', seperti model ukiran Jawa Timur-Madura. Bahkan, di sebuah kelenteng di Surabaya ditemukan ragam ukiran dari kebudayaan Eropa yang menjadi hiasan altar sebuah arca dewa.

Masih banyak lagi simbol yang berupa benda, lambang, atau warna yang tidak dapat disebutkan di sini satu-persatu. Dengan banyaknya berbagai benda, hiasan, dan ornamen yang menyiratkan banyak makna ini maka seseorang dapat belajar kembali banyak hal tentang kebudayaan, seni, dan ajaran-filasafat China dari sebuah bangunan kelenteng.

\section{Kelenteng sebagai Pusat Kegiatan Sosial dan Pembauran Kesenian}

Berhubungan erat dengan acara ritual, kelenteng juga sebagai pusat kegiatan kesenian dan sosial. Banyak kelenteng yang menjadi markas kelompok kesenian tarian Naga-Singa atau Liong Samsi yang sering disebut tarian barongsai. Pelaku kesenian ini tak hanya muda-mudi dari kalangan Tionghoa saja tetapi juga dari berbagai suku di Nusantara. Bahkan, sekarang sebuah kelompok tarian naga yang terkenal di Jawa Tengah adalah kelompok tarian naga Tentara Nasional Indonesia yang bermarkas di daerah Semarang. Pembauran kesenian juga sering terlihat dalam acara arak-arakan ritual gotong Tepekong di Jawa, tarian barongsai bersanding dengan tarian kuda lumping, dan Reog Ponorogo memeriahkan perayaan. 
Upacara ritual Peh Cun yang dirayakan dengan perayaan Perahu Naga selalu menjadi hiburan dan melibatkan masyarakat umum non-Tionghoa. Upacara ritual Cioko atau Sembahyang Rebutan biasanya sekalian disertai acara membagi-bagikan beras dan kebutuhan pokok lainnya kepada masyarakat miskin sekitar kelenteng. Dan masih banyak kegiatan kesenian dan sosial lainnya yang berpusat di kelenteng. Dari sini dapat dilihat bahwa kelenteng selain berfungsi sebagai tempat pelestarian kesenian khas China, juga juga sebagai tempat kegiatan sosial yang semakin mendekatkan warga kelenteng dengan masyarakat sekitarnya.

\section{Masa Suram Kelenteng}

Menilik berbagai fungsinya, tidaklah disangkal bila kelenteng menjadi salah satu pusat kegiatan masyarakat Tionghoa di Indonesia. Akan tetapi, pemerintahan Orde Baru membawa perubahan besar. Pada masa itu, kaum Tionghoa di Indonesia, walaupun secara ekonomi tampak dimanjakan tetapi dalam hal kebudayaan mereka dipasung. Berbagai kebijaksanaan pemerintah tahun 1966-1967 yang isinya sangat diskriminatif terhadap kaum Tionghoa membuat hampir segala bentuk kebudayaan Tionghoa di Indonesia lumpuh. Bahasa dan aksara China dilarang digunakan. Berbagai macam pertunjukan, seperti wayang potehi dan tarian barongsai menjadi pemandangan langka. Upacara ritual gotong tepekong hampir tak terlihat lagi. Bahkan, nama Tionghoa yang merupakan identitas terunik bagi seseorang pun harus dihapus dan diganti.

Ajaran Konghucu dan Taoisme diharamkan dan akibatnya kelenteng pun tak luput dari sasaran. Sebagian besar kelenteng harus mengubah diri menjadi Vihara yang lebih mengacu sebagai tempat ibadat agama Budha sedangkan ajaran Taoisme dan Konghuchu dianggap sebagai sampingan saja dan harus berlindung dibalik agama Budha. Akibatnya, di beberapa kelenteng, arca tokoh dari ajaran Budha yang dulunya sebagai arca tambahan ditempatkan di altar utama. Bahkan, di beberapa kelenteng yang sebelumnya tidak menganut ajaran Budha, mencari keselamatan dengan men-Tri Dharma-kan diri dengan memasukkan arca dari ajaran Budha. Fisik bangunan kelenteng pun menjadi korban. Jangankan membangun atau memperluas bangunan, memperbaiki kerusakan pun tak berani dilakukan. Kalaupun dilakukan, pasti dengan sembunyi-sembunyi. Akibatnya, sampai tahun 1997, banyak sekali bangunan kelenteng dalam kondisi mengenaskan.

Demi menyambung nyawa dan menjamin keselamatan dirinya, warga Tionghoa di Indonesia pun banyak yang berlindung dalam agama resmi yang ditetapkan pemerintah. Kaum muda Tionghoa yang lahir setelah tahun 1960 seperti tak lagi mengenali budayanya. Kaum tuanya mungkin menyadari kesenjangan budaya ini tetapi tekanan politik terasa lebih berat. Mereka lebih mengutamakan keselamatan generasi mudanya walaupun harus kehilangan sebagian besar budayanya. Bahkan, beberapa diantara kaum tua Tionghoa ada yang sengaja menakut-nakuti kaum mudanya untuk tidak belajar budaya leluhurnya demi keselamatan keluarga. Dan akibatnya dapat dibayangkan bila 30 tahun kemudian terjadi kesenjangan budaya antara generasi tua dan generasi muda Tionghoa di Indonesia. Memang unik juga nasib bangsa China perantauan ini, mereka harus/terpaksa mengorbankan sebagian harga dirinya, yaitu kebudayaannya untuk mempertahankan hidup dan memperoleh bentuk harga diri yang lain: kekuatan ekonomi. Yin dan Yang!

\section{Benteng Terakhir dan Titik Awal Perkembangan Kebudayaan Tionghoa}

Walaupun begitu, kebudayaan Tionghoa tidaklah lantas lenyap seluruhnya begitu saja. Sisasisa kebudayaan ini masih tersimpan dan dilakukan semampunya di dalam kelenteng. Meskipun sebagian rusak dan tak terawat, bangunan kelenteng masih menyimpan berbagai arca, ukiran, lukisan, dan berbagai ornamen. Secara sangat terbatas dan sembunyi-sembunyi, berbagai acara ritual, kebudayaan, dan kegiatan sosial masih dilakukan di dalam lingkunga kelenteng. Pendeknya, selama hampir 32 tahun pemerintahan Orde Baru, kelenteng berfungsi menjadi benteng terakhir kebudayaan Tionghoa di Indonesia. 
Setelah menjadi salah satu tumbal politik melalui peristiwa anti-Tionghoa yang mengenaskan Mei 1998, Era Reformasi membawa banyak perubahan di republik ini. Era pemerintahan baru di bawah Presiden Gus Dur dan Megawati mencabut beberapa kebijaksanaan yang diskriminatif terhadap masyarakat Tionghoa. Walaupun masih terjadi beberapa kendala di lapangan, tetapi kebudayaan Tionghoa kembali menggeliat bangkit. Malahan diberbagai tempat atau kalangan ditengarai terjadi eforia atau malah latah kebudayaan Tionghoa.

Kelenteng kembali menjadi pusat kegiatan. Banyak bangunan kelenteng mulai diperbaiki atau bahkan direnovasi besar-besaran. Tarian barongsai yang terlihat meramaikan berbagai acara. Upacara ritual arak-arakan dewa 'gotong tepekong' yang banyak mengikut sertakan kebudayaan China, seperti pakaian, musik, dan tarian mulai dilaksanakan di berbagai kota. Kelenteng kembali ramai didatangi oleh lebih umat Tionghoa yang ingin bersembahyang. Pendeknya kelenteng menjadi salah satu titik awal bangkitnya kembali kebudayaan Tionghoa di Indonesia.

Namun, tiga puluh tahun lebih dalam belenggu budaya membuat sebagian besar umat Tionghoa kehilangan pengetahuan rohani dan budayanya. Sebuah kenyataan pahit menjadi pemandangan sehari-hari dalam kelenteng, yaitu banyak umat Tionghoa yang datang ke kelenteng hanya bersembahyang depan arca para dewa tanpa mengerti lagi siapa dan apa sebenarnya ajaran para dewa-dewi tersebut. Pokoknya bersoja, menancapkan hio dan menuang minyak di altar dewa tersebut, beres urusan.

Juga dapat diperhatikan, bila memasuki sebuah kelenteng, perhatian umat hanya tertuju arca para dewa-dewi saja. Isi keleteng lainnya seolah bukanlah hal yang patut diperhatikan, atau paling tidak dinikmati keindahannya. Ditambah lagi, entah karena ketidaktahuan, ketidakmampuan, atau bahkan ketidakpedulian dari umat dan pengurus kelenteng, ukiran atau lukisan yang menyimbolkan ajaran banyak hal itudianggap hiasan belaka sehingga kerap tampak tak terawat, kotor tertutup debu, atau malahan hitam tak terlihat sama sekali terkena asap hio bertahun-tahun. Jangankan untuk mengerti simbol apa yang terkandung, bahkan sering kali mereka juga tidak tahu lagi apa sebenarnya hewan, tumbuhan, atau cerita apa yang terukir atau terlukis tersebut.

Memang ada usaha dari beberapa kaum terpelajar Tionghoa untuk mulai memperhatikan masalah ini. Akan tetapi, memang bukanlah hal yang mudah untuk menghadapi akibat belenggu budaya yang telah membuat sebagian besar kaum Tionghoa tua terlanjur apatis dan kaum mudanya tak lagi mengenali keagungan budayanya. 


\section{PENUTUP}

Salah satu cara yang patut dicoba untuk mengenalkan dan membangkitkan kembali kebudayan Tionghoa kepada masyarakat Tionghoa di Indonesia adalah mengajak kaum muda Tionghoa kembali ke kelenteng. Tujuannya adalah bukan untuk melepaskan agama yang sekarang sudah mereka anut tetapi lebih sebagai titik awal untuk mengenalkan kembali nilai moral, sejarah, dan kebudayaan Tionghoa yang terkandung dalam kelenteng.

Ternyata cara inipun menghadapi kendala kesiapan sumber daya manusia dan sarana penunjang. Beberapa dari kaum muda Tionghoa merasa kecewa karena pertanyaan mereka dijawab sekenanya oleh keluarga dan para pengurus kelenteng yang mungkin memang tidak mengerti tentang kelentengnya sendiri. Buku tentang hal ini masih sulit di dapat atau terlalu mahal. Kendala bahasa juga berperan besar. Tulisan nama dewa-dewi dalam aksara latin yang kerap kali berbeda dari kelenteng satu dengan yang lain sering membuat bingung kaum muda Tionghoa yang baru belajar.

Mungkin sekolah, universitas, atau lembaga Tionghoa perlu mengadakan semacam kunjungan budaya ke kelenteng dengan pembimbing yang baik dan prasarana yang menunjang. Film dokumenter merupakan salah satu sarana yang sangat menunjang dan lebih menarik buat kaum muda untuk belajar. Beberapa stasiun TV sudah mulai membuat dan menyiarkannya tetapi rasanya masih perlu lagi pendalaman materi sejarah dan budayanya. Sumber beritanya yang sering kali hanya berasal dari pengurus kelenteng setempat yang malah terkadang memberi informasi yang kurang tepat. Pelafalan istilah dalam bahasa China dialek apapun juga masih menjadi kendala bagi para reporter media massa sehingga yang hal disampaikan menjadi kurang tepat dan terkadang malah memberikan informasi yang salah.

Kelenteng memang boleh dikatakan berhasil menjadi benteng terakhir budaya Tionghoa di Indonesia menghadapi tekanan Orde Baru tetapi memang masih perlu usaha yang lebih keras dan waktu yang lebih panjang untuk menjadikannya titik awal kebangkitan dan penyebaran kembali budaya Tionghoa kepada masyarakat Tionghoa di Indonesia sendiri. 


\section{DAFTAR PUSTAKA}

Hean-Tatt, Ong. 1996. Simbolisme Hewan Cina. Jakarta: Kesaint Blanc.

Herwiratno, Martinus. 2001. Laporan Hasil Riset Kebudayaan Cina di Indonesia untuk Film Cabaukan. Jakarta

. 2002. Laporan Hasil Riset Kebudayaan Cina di Jawa untuk serial Film Dokumenter: Kelenteng-kelenteng di Pesisir Utara Jawa. Jakarta.

. Februari 2003. Laporan Hasil Riset Kebudayaan Cina di Indonesia untuk Sinetron Perayaan Imlek: Tahun Baru Terindah, TV-7. Jakarta.

. September 2001 “Perayaan Dewa Sampokong - Semarang.” Swara Chantika. Jakarta.

April 2002. "Malam 1 Suro di Gunung Kawi.” Swara Chantika. Jakarta.

25 Agustus 2001. “Semarang Kota 1000 Kelenteng.” Harian Sinar Harapan. Jakarta.

Indonesian Journal of Social and Cultural Anthropology, Th XXVII no. 71, Mei-Agustus 2003, Departemen Antropologi Fak Ilmu Sosial dan Ilmu Politik, Universitas Indonesia.

Kingsley, Rebecca. 1998. Chinese Gods \& Myths. Singapore: Quantum Books Ltd.

Kwa Thong Hay. 1990. Dewa-dewi Kelenteng. Semarang: Yayasan Kelenteng Sampokong.

Lip, Evelyn. 1981. Chinese Temples and Deitis. Singapore: Times Books International.

Pan, Lynn (General Editor). 2002. The Encyclopedia of Chinese Overseas. Chinese Heritage Centre, Archipelago Press \& Landmark Books. Singapore.

Salmon, Cl and D. Lombard. 1985. Klenteng-klenteng Masyarakat Tionghoa di Jakarta. Jakarta: Yayasan Cipta Loka Caraka.

Suryadinata, Leo. 2002. Negara dan Etnis Tionghoa - Kasus Indonesia. Jakarta: Pustaka LP3S Indonesia.

Suryadinata, Leo. 1988. Kebudayaan Minoritas Tionghoa di Indonesia. Jakarta: PT Gramedia.

Wolfram, Eberhard. 1990. Dictionary of Chinese Symbols. Singapore: Federal Publications.

Williams, CAS. 1998.Chinesse Symbolism and Art Motifs. Tokyo: Tuttle Publishing. 